\title{
Livedoid Vasculopathy Associated with Antiphospholipid Antibody Presenting with Leg Ulcer
}

\author{
Sunil V. Kapur ${ }^{1,2} \cdot$ Jitendra S. Oswal $^{1}$ \\ Received: 14 January 2020 / Accepted: 29 April 2020 / Published online: 26 May 2020 \\ (C) Dr. K C Chaudhuri Foundation 2020
}

To the Editor: A 15-y-old boy presented with recurrent nonhealing ulcer on the right leg for the last four years. On local examination there was a single $2 \times 2 \mathrm{~cm}$, painful, deep ulcer above the right malleolar region with surrounding erythema and swelling. Investigations revealed hemoglobin of $11.2 \mathrm{~g} / \mathrm{dl}$, white blood cell count of $10,500 / \mathrm{mm}^{3}$, and a platelet count of 2.1 lakhs $/ \mathrm{mm}^{3}$. Erythrocyte sedimentation rate was raised $(35 \mathrm{~mm} / \mathrm{h})$ with normal C-reactive protein $(4 \mathrm{mg} / \mathrm{L})$. Urine routine, renal and liver function tests, blood sugar levels were within normal limits. Viral serology (HIV, HBsAg, HCV) was negative with normal limb doppler studies. ANA, anti-dsDNA and ANCA were negative. Antiphospholipid workup revealed positive anti-cardiolipin IgM antibody and positive lupus anticoagulant. Serum homocysteine, lipoprotein levels, protein $\mathrm{S}$, protein $\mathrm{C}$ and antithrombin III functional activity were normal. Factor V Leiden mutation and serum cryoglobulins were negative. Deep skin biopsy revealed intraluminal thrombosis of the small dermal vessels without significant inflammatory infiltrate suggestive of Livedoid vasculopathy (LV). Antithrombotic therapy was initiated with subcutaneous administration of low-molecular-weight heparin along with oral hydroxychloroquine.

LV is a rare non-inflammatory occlusion of the small vessels of the skin due to thrombosis and deposition of fibrin in the vessel walls, affecting mainly young women and mimicking vasculitis [1]. Histopathological examination of the ulcers is diagnostic of LV. Neutrophil infiltration and leukocytoclasia are usually absent in LV (unlike in vasculitis) [2]. LV can be

Jitendra S. Oswal

dmd.bharatihospital@gmail.com

Sunil V. Kapur

Sunilvkapur@gmail.com

1 Department of Pediatrics, Bharati Vidyapeeth University Medical College Hospital \& Research Centre, Pune 411043, India

2 Department of Pediatric Rheumatology, Apollo Cradle Hospital, Pune, India associated with thrombophilias, fibrinolytic disorders, autoimmune diseases, antiphospholipid syndrome and malignancy [3]. In our patient, LV was associated with positive anticardiolipin IgM antibody and lupus anticoagulant, which has been reported previously in adults $[4,5]$ but has not been reported in children. Based on the etiology, LV treatment options include antiplatelet agents, anticoagulants, antifibrinolytic agents, vasodilators, immunosuppressive medications, and intravenous immunoglobulins. We initiated treatment with low-molecular-weight heparin and hydroxychloroquine with significant clinical improvement and normalization of ESR at three months of follow up. To the best of our knowledge this is the first case reported from India of juvenile LV associated with antiphospholipid antibody. We report this case due to the rarity of this condition and to increase awareness of the same amongst Pediatricians.

\section{Compliance with Ethical Standards}

Conflict of Interest None.

\section{References}

1. Alavi A, Hafner J, Dutz JP, et al. Livedoid vasculopathy: an indepth analysis using a modified Delphi approach. J Am Acad Dermatol. 2013;69:1033-42.

2. Bard JW, Winkelmann RK. Livedo vasculitis: segmental hyalinisation of the dermis. Arch Dermatol. 1967;96:489-99.

3. Vasudevan B, Neema S, Verma R. Livedoid vasculopathy: a review of pathogenesis and principles of management. Indian J Dermatol Venereol Leprol. 2016;82:478-88.

4. Serra S, Saavedra MJ, Salvador MJ, Reis JP, Malcata A. Livedoid vasculitis in a patient with antiphospholipid syndrome. Acta Reumatol Port. 2010;35:249-53.

5. Grasland A, Crickx B, Blanc M, Pouchot J, Vinceneux P. Livedoid vasculopathy (white atrophy) associated with anticardiolipin antibodies. Ann Med Interne (Paris). 2000;151:408-10.

Publisher's Note Springer Nature remains neutral with regard to jurisdictional claims in published maps and institutional affiliations. 